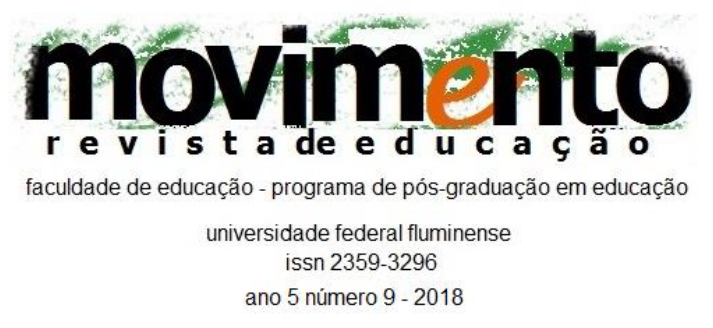

\title{
ESTRATIFICAÇÃO EDUCACIONAL E DESIGUALDADES NO SUCESSO ACADÊMICO EM MEDICINA E EM SERVIÇO SOCIAL
}

\author{
Lucinete Marques Lima \\ Universidade Federal do Maranhão \\ Maranhão, MA, Brasil \\ Angelo Rodrigo Bianchin \\ Universidade Federal do Maranhão \\ Maranhão, MA, Brasil \\ Ellen Patrícia Braga Pantoja \\ Universidade Federal do Maranhão \\ Maranhão, MA, Brasil
}

\begin{abstract}
Resumo
O artigo discute a estratificação educacional no ensino superior por campo de estudo, tomando por objeto de análise os cursos de Medicina e Serviço Social, ofertados pela Universidade Federal do Maranhão (UFMA), considerando critérios e percentuais de ingresso por categorias sociais em seis anos, a movimentação acadêmica no percurso estudantil e o perfil do estudante concluinte. Os resultados indicam a presença de estratificação vertical e horizontal, reforçada por diferenciações quanto às categorias sociais que tiveram acesso e sucesso acadêmico em Medicina e em Serviço Social. Palavras-chave: Estratificação educacional; Medicina; Serviço Social.
\end{abstract}

\section{EDUCATIONAL STRATIFICATION AND INEQUALITY IN ACADEMIC SUCCESS IN MEDICINE AND SOCIAL WORK}

\begin{abstract}
The article discusses educational stratification in higher education by field of study, taking as object of analysis the courses of Medicine and Social Work, offered by a university in the Northeast of Brazil, considering criteria and percentages of entry by social categories in six years, the academic movement in the student path and the concluding student profile. The results indicate the presence of vertical and horizontal stratification, reinforced by differences in the social categories that had access and academic success in Medicine and Social Work.

Keywords: Educational stratification; Medicine; Social Work.
\end{abstract}




\section{movimento \\ faculdade de educação - programa de pós-graduação em educação \\ universidade federal fluminense \\ issn 2359-3296 \\ ano 5 número 9 - 2018}

\section{ESTRATIFICACIÓN EDUCACIONAL Y DESIGUALDADES EN EL ÉXITO ACADÉMICO EN MEDICINA Y SERVICIO SOCIAL}

\section{Resumen}

El artículo discute la estratificación educativa en la enseñanza superior por campo de estudio, tomando por objeto de análisis los cursos de Medicina y Servicio Social, ofrecidos por una universidad de la región Nordeste de Brasil, considerando criterios y porcentajes de ingreso por categorías sociales en seis años, el movimiento académico en el recorrido estudiantil y, el perfil del estudiante concluyente. Los resultados indican la presencia de estratificación vertical y horizontal, reforzada por diferenciaciones relativas a las categorías sociales que tuvieron acceso y éxito académico en Medicina y en el Servicio Social.

Palabras clave: Estratificación educativa; Medicina; Servicio Social.

\section{Introdução}

Este artigo discute a estratificação educacional nas suas dimensões vertical e horizontal nos cursos de Medicina e de Serviço Social em uma Instituição Federal de Educação Superior (IFES) da região Nordeste, a partir de evidências e relações entre dados primários e secundários. Dessa forma, analisa-se a influência da origem socioeconômica e cultural no acesso à educação superior nesses dois cursos.

A escolha dos cursos faz-se pela diferença de valorização na hierarquia de prestígio social, não só por serem de campos científicos mais ou menos valorizados na sociedade capitalista, como também pelo valor simbólico do diploma, do status e do poder profissional legitimados na consciência coletiva e nas instituições. Além disso, considerou-se o valor de troca dos serviços no mercado de trabalho - Medicina, na área de Saúde, e Serviço Social, antes concebido na periferia dessa área e atualmente vinculado à de Ciências Sociais Aplicadas.

Historicamente, o curso de Medicina apresenta-se com alta seletividade, favorecendo segmentos mais privilegiados em relação à posição social e ao 


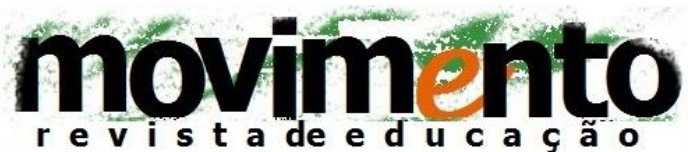 \\ faculdade de educação - programa de pós-graduação em educação \\ universidade federal fluminense \\ issn 2359-3296 \\ ano 5 número 9 - 2018}

capital cultural. Por outro lado, a graduação em Serviço Social seria mais acessível às classes populares. Também, a escolha faz-se com base em diferenciações qualitativas existentes entre as áreas, apontadas por pesquisas, em especial as realizadas por Ribeiro e Schlegel (2015), acerca da participação em termos do gênero, da cor/raça, das remunerações associadas às carreiras e das possibilidades de mobilidade social.

Além disso, considera-se o fato desses cursos localizarem-se em uma universidade pública de ensino, de pesquisa e de extensão, representando uma diferença qualitativa do tipo institucional que aprofunda a seletividade de capital cultural e, consequentemente, de condições socioeconômicas, legitimada no discurso de meritocracia. Vale lembrar que, de modo geral, o curso de Medicina no país é ofertado por instituições públicas, cujas despesas de custeio são arcadas integralmente pelo Estado, o que faz com que a gratuidade do curso, comparada ao alto valor das mensalidades cobradas nas instituições privadas, intensifique a competitividade no ingresso do estudante.

A partir de 1990, com as reformas da educação superior no Brasil, ocorre um processo de expansão das vagas nas instituições privadas - tendência que se manteve na década seguinte, apesar de maiores investimentos no setor público, como a expansão e a interiorização das universidades públicas.

Esse processo de expansão dialoga com a ideia de democratização do acesso à educação superior. A proposta é romper com a tendência de ocupação de vagas por grupos sociais privilegiados, principalmente em cursos e em instituições considerados de maior prestígio social.

Nos últimos quinze anos, quatro medidas normativas ou programáticas se desenvolvem com a finalidade de inclusão da diversidade social na composição 


\section{movimento \\ faculdade de educação - programa de pós-graduação em educação \\ universidade federal fluminense \\ issn 2359-3296 \\ ano 5 número 9 - 2018}

da população estudantil no ensino superior: Programa Universidade para Todos (Prouni), Programa de Apoio a Planos de Reestruturação e Expansão das Universidades Federais (Reuni), Sistema de Seleção Unificado (Sisu) e algumas outras políticas de ação afirmativas.

O Prouni direciona-se para a concessão de bolsas no setor privado por meio de isenção fiscal, o que alivia a pressão sobre as instituições públicas. Os demais estão relacionados ao ingresso na graduação em instituições federais. O Reuni criou mais vagas públicas e forçou a expansão e a interiorização de universidades e de cursos, facilitando a entrada de estudantes dessas regiões com dificuldades de deslocamentos geográficos. O Sisu e as políticas de ação afirmativa, além de permitirem maior movimentação inter-regional dos discentes, seleciona de forma distinta as categorias sociais para o ingresso nas universidades, almejando, assim, a uma certa superação da desigualdade educacional.

O Sisu foi criado em 2009 como um sistema informatizado, gerenciado pelo Ministério da Educação (MEC), no qual as IFES ofereciam, por adesão voluntária, vagas para os cursos de graduação a candidatos participantes do Exame Nacional do Ensino Médio (Enem). Após a Lei o $12.711 / 2012^{1}$, as regras do Sisu passaram a prever seis possíveis rotas de concorrência: 1) Ampla concorrência; 2) ações afirmativas próprias de cada instituição; 3) estudantes Pretos, Pardos e Indígenas (PPIs) oriundos de escolas públicas, com renda familiar de até um salário mínimo e meio; 4) estudantes PPIs, com renda familiar superior a um salário mínimo e meio; 5) estudantes oriundos de escolas públicas, com familiar de até um salário mínimo e meio; 6) estudantes oriundos de escolas públicas, com renda familiar superior a um salário mínimo e meio.

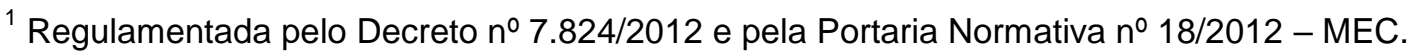




\section{movimento \\ faculdade de educação - programa de pós-graduação em educação \\ universidade federal fluminense \\ issn 2359-3296 \\ ano 5 número $9-2018$}

Há consenso sobre os avanços na inclusão de diferentes categorias sociais na educação superior com as políticas implementadas a partir de 2005. Entretanto, existem estudos que apontam a permanência de estratificação educacional no ingresso por tipo de cursos ou de instituições, com implicações no percurso e no sucesso acadêmico. Diante desse problema, este estudo busca apreender a presença de estratificação educacional em Medicina e em Serviço Social ou os indícios de superação por meio das políticas de reserva de vagas (Lei no 12.711/2012) incorporadas nas regras do Sisu.

Tal estudo é de natureza bibliográfica, documental e empírico. Bibliográfico porque demarca conceitos de estratificação educacional e fundamenta a análise de suas dimensões nos cursos em análise e documental porque se fundamenta em matérias normativas e documentos oficiais. Ainda, empírico por levantar dados fornecidos pelo Sistema Integrado de Gestão de Atividades Acadêmicas (SIGAA) sobre a movimentação acadêmica (ingresso, cancelamento e conclusão) e por analisar elementos secundários do Questionário Socioeconômico (QSE) do Exame Nacional de Desempenho de Estudantes (Enade) aplicado aos concluintes dos cursos de Medicina e de Serviço Social (anos 2010, 2013 e 2016) e sistematizados pelo INEP. Esses questionários informam sobre o perfil socioeconômico e cultural dos discentes concluintes.

\section{Estratificação na educação superior: base conceitual explicativa}

O conceito de estratificação social relaciona-se no campo sociológico com a classificação de indivíduos ou de grupos na pirâmide social conforme a hierarquia da posição ou o status com implicações em diferenças ou 


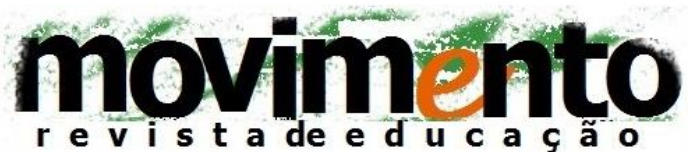 \\ faculdade de educação - programa de pós-graduação em educação \\ universidade federal fluminense \\ issn 2359-3296 \\ ano 5 número 9 - 2018}

desigualdades no acesso a bens materiais e simbólicos e nas relações em sociedade. Portanto, liga-se a uma realidade desigual e excludente, em que há poucas possibilidades de mobilidade e de acesso a direitos.

Enquanto variante do conceito sociológico, a estratificação educacional definese na relação entre a origem socioeconômica e o acesso aos níveis educacionais, ocorrendo nas dimensões vertical e horizontal (MONT'ALVÃO, 2016). A primeira dimensão está voltada para a análise do efeito das origens sociais sobre o alcance educacional ou sobre as chances de estudantes completarem as transições educacionais; a segunda, por sua vez, busca desvelar em que medida as origens sociais influenciam no tipo ou na qualidade da educação recebida pelos alunos, principalmente no ensino superior. Para explicar essas dimensões, recorre-se às hipóteses da desigualdade maximamente mantida (Maximally Maintained Inequality - MMI) e/ou da desigualdade maximamente efetivada (Effectively Maintained Inequality - EMI).

A hipótese da desigualdade maximamente mantida, formulada por Raftery e Hout (1993), citados por Mont'Alvão (2011; 2016), Prates e Collares (2014) e Picanço e Morais (2016), refere-se à transição entre os ciclos ou os níveis educacionais, prevendo que as barreiras educacionais para jovens em desvantagem surgem em um sistema educacional no qual os principais lugares são limitados e as vagas disponíveis são ocupadas por jovens oriundos de classes sociais privilegiadas.

Hout (2006), explanando sobre essa hipótese, afirma que essas barreiras educacionais persistirão enquanto houver jovens de classe alta com aspirações não cumpridas. Uma vez que haja saturação na demanda da classe privilegiada por um determinado nível de educação, elas diminuirão, o que 


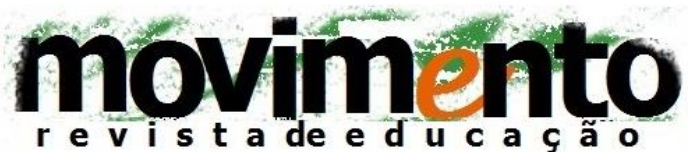 \\ faculdade de educação - programa de pós-graduação em educação \\ universidade federal fluminense \\ issn 2359-3296 \\ ano 5 número 9 - 2018}

permitirá aos demais estudantes aproveitarem as oportunidades educacionais, deslocando a pressão para as transições seguintes do sistema escolar.

Diversos estudos internacionais foram realizados com a finalidade de comprovar a hipótese da desigualdade maximamente mantida (MMI) - entre eles, Shavit e Blossfield e o próprio Hout, ambos em 1993. De acordo com Prates e Collares (2014), a principal conclusão dessas pesquisas foi no sentido de que a expansão educacional pode funcionar como um mecanismo de desvio da pressão exercida pelas classes sociais mais baixas por educação, criando, assim, uma ilusão de que as diferenças estariam sendo reduzidas, quando, de fato, seriam mantidas no mesmo nível.

Em relação à dimensão horizontal, destaca-se a hipótese da desigualdade maximamente efetivada (EMI) proposta por Samuel Lucas em 2001 (apud MONT'ALVÃO, 2016). De acordo com ela, quando um determinado nível educacional se aproxima da sua universalização, a estratégia seguida pelos grupos privilegiados é garantir o acesso a diferenças qualitativas. Desse modo, as disparidades nas chances de alcance ao ensino passam a ser substituídas pelas dificuldades de ingresso aos caminhos mais seletivos e prestigiados.

Prates e Collares (2014) mencionam pesquisas de Shavit et al. (2007) realizadas em quinze países que buscaram medir as chances de acesso à educação superior controladas pela classe social dessas nações. Com base nos resultados, verificou-se que há pelo menos três modos pelos quais a disparidade de acesso e de participação na educação superior, mesmo em situação de expansão, pode se manter: desigualdades entre os setores institucionais (público ou privado), entre os tipos de instituições (universidades, centros universitários, faculdades, institutos tecnológicos etc.) e entre áreas de estudo e suas diferentes oportunidades ocupacionais. 


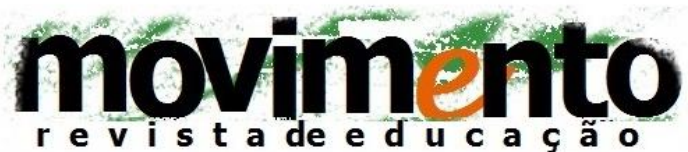 \\ faculdade de educação - programa de pós-graduação em educação \\ universidade federal fluminense \\ issn 2359-3296 \\ ano 5 número 9 - 2018}

Cabe destacar que os estudos sobre a expansão educacional e a sua relação com a questão das desigualdades adquiriram maior amplitude com a passagem da educação secundária do sistema de elite para o de massa, com evidências, em vários países, de que, apesar do alargamento, os indicadores de disparidades tendiam a se manter, mostrando-se pouco satisfatórios.

De acordo com Picanço e Morais (2016), essa passagem só veio a ocorrer no Brasil por volta dos anos 2000, quando então a literatura nacional passou a ampliar seu escopo analítico e empírico, promovendo estudos no campo da estratificação educacional, com análises dos efeitos das origens sociais nos resultados educacionais alcançados pelos indivíduos.

Especificamente, essas pesquisas observaram características socioeconômicas e culturais dos discentes no ingresso e na saída das diversas transições do sistema de ensino. Além disso, identificaram que os mecanismos pelos quais essa entrada e essa saída se relacionam com a questão da mobilidade social, cujo aumento estaria condicionado à redução da desigualdade de oportunidades educacionais.

Desde a aprovação da Lei de Cotas, verifica-se uma profunda mudança no tocante às regras de acesso ao ensino superior público no Brasil. Com efeito, observa-se uma crescente heterogeneidade do perfil discente nas IFES em termos de suas origens sociais e culturais. Entretanto, faz-se necessária uma análise mais acurada acerca dessa heterogeneidade, principalmente quando são identificadas algumas tensões que põem em xeque a democratização do ingresso.

Dessa forma, é intenção desta pesquisa relacionar as teorias e as hipóteses explicativas da estratificação educacional com dados da movimentação 


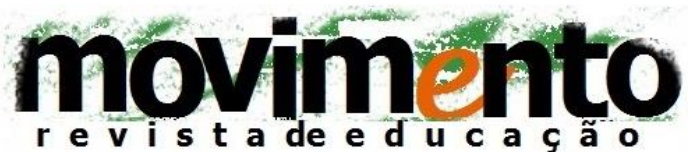 \\ faculdade de educação - programa de pós-graduação em educação \\ universidade federal fluminense \\ issn 2359-3296 \\ ano 5 número 9 - 2018}

acadêmica do estudante. Além disso, propomo-nos a pensar o perfil do concluinte dos cursos de Medicina e de Serviço Social, considerando as implicações das dimensões vertical e/ou horizontal no seu acesso direto e na reprodução das desigualdades sociais.

\section{Movimentação acadêmica na Medicina e em Serviço Social na IFES}

Os cursos de Medicina e Serviço Social foram criados inicialmente como faculdades isoladas, na década de 1950, sob direção da Igreja Católica no Maranhão e, posteriormente, integrados à IFES no processo de federalização em tempos do governo militar. Tais cursos, situados na capital do estado, desenvolvem atividades de ensino, de pesquisa e de extensão presenciais.

Desde a década de 1990 até 2007, essa instituição utilizava duas modalidades de seleção para o ingresso na graduação: $50 \%$ das vagas para o Vestibular e o restante para o Processo Seletivo Gradual (PSG). Esse último era composto por prova relacionada a cada série do ensino médio para os candidatos concluintes. No entanto, não havia nessa modalidade qualquer inclusão da diversidade de categorias sociais, o que acabava por homogeneizar a participação com a predominância dos estudantes das escolas privadas.

Diante do diagnóstico de que o PSG não favorecia o ingresso dos alunos das escolas públicas, a IFES, por meio da Resolução do Conselho de Ensino Pesquisa e Extensão (CONSEPE de 2006), regulamentou a extinção gradativa dessa modalidade de seleção e instituiu políticas de ações afirmativas da seguinte forma: $30 \%$ das vagas da graduação para o PSG e $70 \%$ para 0 Vestibular. Estas eram redistribuídas, sendo $50 \%$ para a categoria universal, $25 \%$ para cota de negros e $25 \%$ para candidato que tenha cursado todo o 


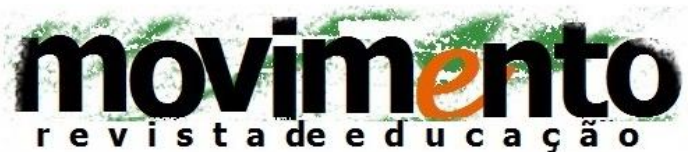 \\ faculdade de educação - programa de pós-graduação em educação \\ universidade federal fluminense \\ issn 2359-3296 \\ ano 5 número 9 - 2018}

ensino médio em escola pública. Também era ofertada uma vaga cortesia para pessoa com deficiências e uma para indígena (em caso de não preenchimento, elas seriam desativadas).

Essa Resolução vigorou nos ingressos de 2007 e2008. Em 2007, uma outra do CONSEPE também instituiu uma Comissão de Validação de Matrícula da Cota de Negros com base em critérios fenótipos. O ingresso nos cursos de graduação em 2009 foi orientado por outra Resolução, aprovada em 2008, consolidando a extinção da modalidade PSG e distribuindo a totalidade de vagas nas categorias: $50 \%$ para universal, $25 \%$ escola pública, $25 \%$ negro e ainda 4 vagas na categoria especial (duas para índio e duas para pessoa com deficiência). Ainda em 2009, a instituição fez adesão ao Sisu como critério exclusivo de acesso a partir do ano seguinte, submetendo-se às portarias do MEC orientadoras do processo seletivo.

Após a Lei oㅜ 12.711 de 2012 e as regulamentações específicas, o ingresso em cursos de graduação nessa instituição ocorreu em três categorias: universal ou ampla concorrência, correspondendo a $50 \%$ das vagas; escola pública com $50 \%$ e 2 vagas para pessoa com deficiência. A categoria de escola pública se subdividia da seguinte forma: a) estudante egresso de escola pública com renda familiar bruta de até 1,5 salários mínimos per capita, desdobrando-se em dois grupos - aqueles que se autodeclararam pretos, pardos ou indígenas e aqueles que não se autodeclararam pretos, pardos ou indígenas; b) estudantes egressos de escolas públicas, independente da renda, também dividido em dois grupos - aqueles que se autodeclararam pretos, pardos ou indígenas e aqueles que não se autodeclararam pretos, pardos ou indígenas. Assim, do total de vagas em cada curso, subtraía-se duas especiais (candidato com deficiência e indígena) e as demais eram divididas igualmente em universal e escola pública. 


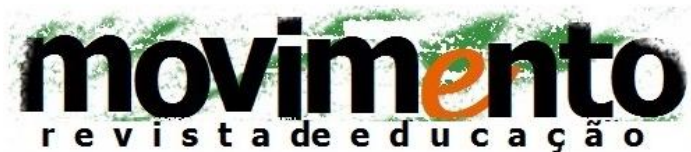 \\ faculdade de educação - programa de pós-graduação em educação \\ universidade federal fluminense \\ issn 2359-3296 \\ ano 5 número 9 - 2018}

$\mathrm{Na}$ análise da estratificação educacional nas dimensões vertical e horizontal nos cursos de Medicina e de Serviço Social, a princípio, recorreu-se à movimentação acadêmica a partir dos relatórios gerados pelo Sistema Integrado de Gestão de Atividades Acadêmicas (SIGAA), buscando indícios da situação acadêmica (matrícula inicial, ativos, trancados, cancelados e curso concluído). Nesse sentido, levantaram-se dados do ano de ingresso dos concluintes dos dois cursos que fizeram ENADE em 2010, 2013 e 2016, bem como dos ingressantes a partir do SISU nesses anos citados. Essas informações podem sinalizar para interpretações relevantes sobre o objeto de pesquisa.

Inicialmente, faz-se uma análise da movimentação acadêmica antes do Sisu, quando a instituição ainda possuía considerável autonomia para deliberar sobre os seus processos seletivos (conforme LDB de 1996). Priorizamos 0 ingresso de Medicina em 2005 e 2008 em razão de serem concluintes em 2010 e 2013, bem como de Serviço Social em 2007 por serem concluintes em 2010.

No ano letivo de 2005 (adicionados os dois semestres), ingressaram 95 estudantes no curso de Medicina, sendo 63 na modalidade vestibular e os outros 32 restantes provavelmente pelo PSG (vestibular seriado), já que essa informação não consta no SIGAA. Sobre os primeiros, 97\% (61 estudantes) concluíram o curso, enquanto dois cancelaram. Os resultados do PSG não foram levantados, mas se considera a adesão predominante de escolas privadas.

Em 2008, já com as políticas de ação afirmativa, ingressam no curso de Medicina 101 estudantes, sendo 32 através da ampla concorrência (94\% de conclusões); 15 na cota para escola pública (100\% de conclusão); 16 negros 


\section{movimento \\ faculdade de educação - programa de pós-graduação em educação \\ universidade federal fluminense \\ issn 2359-3296 \\ ano 5 número 9 - 2018}

(100\% de conclusão); 2 indígenas (100\% de conclusão) e 3 deficiente (1 cancelamento e 2 conclusões de curso). Ainda registraram-se sem informações 33 ingressantes, correspondendo aproximadamente aos 30\% do PSG, último ingresso por essa modalidade. Não há registro de alunos ativos que ingressaram em 2005 e 2008, conforme a expectativa e o tempo de conclusão de curso.

Portanto, nesses dois anos (2005 e 2008), aparentemente não se percebe uma seletividade interna no curso de Medicina nas diferentes categorias de ingresso. Por outro lado, não descartamos a existência de estratificação educacional horizontal ou a hipótese de desigualdade maximamente efetivada (LUCAS, 2001 apud MONT'ALVÃO, 2016). Lembrando que elas afirmam que a posse de recursos culturais e socioeconômicos estejam subjacentes ao ingresso nesse curso, considerando os critérios de ingresso na instituição e outras informações sobre pontuações elevadas no Enem.

Por sua vez, o ingresso no curso de Serviço Social em 2007 (com Enade em 2010) fez-se na vigência da primeira experiência institucional de cotas com as categorias na seguinte forma: 34 estudantes através da ampla concorrência (28 formados e 6 cancelados); 14 alunos de escola pública (10 formados e 4 cancelados); 8 negros (7 formados e 1 cancelado) e 24 registrados sem a categoria de ingresso no SIGAA (sem dúvida pelo PSG, porque se refere a $30 \%$ destinado ao processo).

Em relação às cotas do vestibular, verificam-se os resultados de sucesso acadêmico em ordem decrescente dos percentuais: $87,5 \%$ vestibular negro; $82,5 \%$ vestibular ampla concorrência e $71 \%$ vestibular escola pública. Em relação aos cancelamentos, constata-se: $28 \%$ escola pública; $17 \%$ ampla concorrência e $12 \%$ vestibular negro. Não houve ingresso de pessoa com 


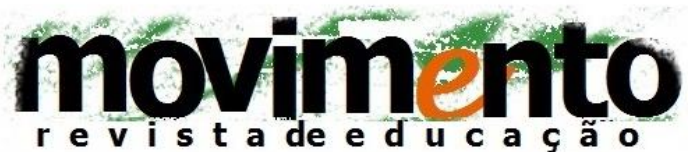 \\ faculdade de educação - programa de pós-graduação em educação \\ universidade federal fluminense \\ issn 2359-3296 \\ ano 5 número 9 - 2018}

deficiência e de indígenas. Cabe destacar que as categorias não estavam vinculadas a critérios socioeconômicos, portanto, não havia discriminação positiva por renda familiar, podendo essa variável estar associada ao ingresso da cota de escola pública com evidências de maior número de cancelamentos e de menor sucesso escolar.

$\mathrm{Na}$ Instituição em foco, a regulamentação do ingresso foi alterada com a adesão ao Sisu, apresentando outra configuração na movimentação acadêmica. Em 2010, a IFES já havia aprovado sua proposta de ações afirmativas no formato da Resolução de 2008 e feito adesão ao Sistema Unificado em 2009, permanecendo com 50\% das vagas na ampla concorrência e redistribuindo as outras $50 \%$ pelas outras categorias de ingresso. Reservava, ainda, as vagas especiais para índios e para pessoas com deficiência. No Sisu de 2010, essas vagas especiais foram subtraídas do conjunto das disponibilizadas e posteriormente as restantes foram distribuídas equitativamente entre as categorias universais e escola pública. Essa última, dividida igualmente nas subcategorias geral ou negro, o que alterou as orientações da Resolução citada anteriormente.

Para as vagas da cota de escola pública - negro, o edital determinava a necessidade de apresentação do candidato à Comissão de Validação de Matrículas para a verificação da compatibilidade entre a informação declarada no Sisu e as características fenotípicas do candidato. O objetivo era garantir à população negra o acesso às vagas específicas.

De acordo com os editais que regulamentaram o ingresso nos cursos de graduação até o ano de 2012, as vagas não ocupadas eram preenchidas mediante a utilização da lista de espera Sisu. A partir dela, eram geradas listas de chamadas até que todas as vagas fossem ocupadas. Sendo assim, as 


\section{movimento \\ faculdade de educação - programa de pós-graduação em educação \\ universidade federal fluminense \\ issn 2359-3296 \\ ano 5 número 9 - 2018}

matrículas que não eram validadas nas cotas de escola pública - geral e de negros - passavam a integrar o número de vagas para a cota de ampla concorrência, uma vez que não era possível se inscrever em diferentes tipos de cotas. Depois do ingresso de 2013, as regras orientaram-se pela Lei no 12.711 de 2012 e pelas regulamentações específicas.

Essa distribuição de vagas por categorias sociais apresenta-se na tabela 1 que sintetiza o número de matrículas realizadas nos cursos de Medicina e de Serviço Social nos períodos de 2010 (primeiro seletivo do SISU), 2013 e 2016 (dois anos após mudanças na redistribuição de vagas por cotas também sociais). Assim, pode-se constatar se houve movimentação acadêmica que sinalize para a inclusão social ou para a permanência da estratificação educacional.

\begin{tabular}{|c|c|c|c|c|c|c|}
\hline \multirow[b]{2}{*}{ Cotas } & \multicolumn{2}{|c|}{2010} & \multicolumn{2}{|c|}{2013} & \multicolumn{2}{|c|}{2016} \\
\hline & Med. & $\begin{array}{l}\text { Serv. } \\
\text { Social }\end{array}$ & Med. & \begin{tabular}{|l|} 
Serv. \\
Social
\end{tabular} & Med. & $\begin{array}{l}\text { Serv. } \\
\text { Social }\end{array}$ \\
\hline Ampla Concorrência & 69 & 41 & 50 & 39 & 48 & 41 \\
\hline $\begin{array}{l}\text { Pretos, Pardos e Indígenas (PPIs) oriundos de } \\
\text { escolas públicas, com renda familiar de até um } \\
\text { salário mínimo e meio }\end{array}$ & \multirow{2}{*}{15} & \multirow{2}{*}{20} & 20 & 16 & 19 & 16 \\
\hline $\begin{array}{l}\text { Pretos, Pardos e Indígenas (PPIs) oriundos de } \\
\text { escolas públicas, com renda familiar superior a um } \\
\text { salário mínimo e meio }\end{array}$ & & & 20 & 18 & 20 & 16 \\
\hline $\begin{array}{l}\text { Estudantes oriundos de escolas públicas, com renda } \\
\text { familiar de até um salário mínimo e meio }\end{array}$ & \multirow{2}{*}{17} & \multirow{2}{*}{20} & 7 & 5 & 6 & 4 \\
\hline $\begin{array}{l}\text { Estudantes oriundos de escolas públicas, com renda } \\
\text { familiar superior a um salário mínimo e meio. }\end{array}$ & & & 5 & 5 & 4 & 4 \\
\hline Deficientes & 1 & 1 & 1 & 1 & 2 & 4 \\
\hline Total & 102 & 82 & 103 & 84 & 99 & 85 \\
\hline
\end{tabular}

Tabela 1: Matrícula inicial dos cursos de Medicina e de Serviço Social em 2010, 2013 e 2016. Fonte: SIGAA da IFES, jun. 2018

Apesar das políticas afirmativas favorecerem o enfrentamento da estratificação vertical e o acesso à educação superior, ainda é possível observar a hipótese da desigualdade maximamente mantida na ocupação das vagas. Na Medicina, 


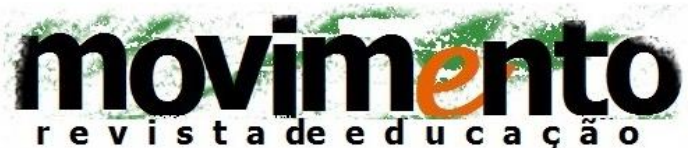 \\ faculdade de educação - programa de pós-graduação em educação \\ universidade federal fluminense \\ issn 2359-3296 \\ ano 5 número 9 - 2018}

as vagas das cotas sociais nem sempre eram preenchidas, conforme critérios prescritos na instituição, em virtude da ocorrência de candidatos que não atendiam às exigências específicas, portanto, retornando para a ampla concorrência. Assim, em 2010, esse curso registra um desequilíbrio na ocupação de vagas pela categoria ampla concorrência para além dos $50 \%$ previstos, com a evidência de 68\% das matrículas do total de 102 ingressantes, permanecendo apenas $32 \%$ nas demais categorias de ingresso. Por sua vez, no curso de Serviço Social, sem tanto prestígio, mantém-se o equilíbrio dos $50 \%$ do total de 82 matrículas na cota ampla concorrência e nas demais cotas previstas.

Se, por um lado, a política de validação da matrícula dos inscritos como negros previa a garantia do acesso de pessoas com essas características fenotípicas nos cursos, por outro, a regulamentação do ingresso aos cursos na IFES reforçava a hipótese da desigualdade maximamente mantida ao desconsiderar, na lista de espera do Sisu, a reserva de vagas pelo tipo de cota social. Cabe destacar que Medicina tradicionalmente manteve-se com posição elevada na hierarquia de prestígio social e com um caráter elitista, portanto, sem grande abertura para o acesso de segmentos populacionais menos privilegiados de condições socioeconômicas e culturais. Esses, muitas vezes, sequer desenvolvem expectativas de ingresso, sentindo-se excluídos do curso antes mesmo do enfrentamento da concorrência de vagas.

Dessa forma, as vagas das cotas sociais às vezes eram pleiteadas por candidatos oriundos das classes privilegiadas, ocasionando barreiras educacionais que precisavam ser enfrentadas para a garantia das políticas de ações afirmativas e, consequentemente, assegurando a diminuição da estratificação vertical e da desigualdade maximamente mantida na educação superior. 


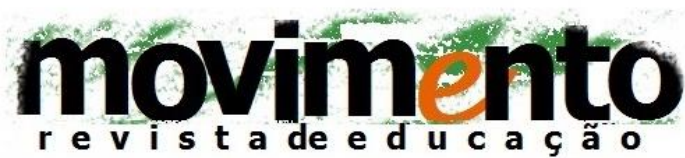 \\ faculdade de educação - programa de pós-graduação em educação \\ universidade federal fluminense \\ issn 2359-3296 \\ ano 5 número 9 - 2018}

Em 2013, o curso de Medicina registrou um total de 103 matrículas, sendo 48,5\% para ampla concorrência e 50,5\% para cotas de escola pública, além da matrícula de um estudante com deficiência. Já o curso de Serviço Social, em um total de 84 matrículas, $46 \%$ foram para ampla concorrência e 53,6\% para as cotas de escola pública. Em 2016, os cursos mantiveram a seguinte distribuição de matrícula inicial: Medicina recebeu 99 estudantes, 48,5\% para ampla concorrência, 49,5\% para escola pública e mais duas para pessoa com deficiência; Serviço Social apresentou o total de 85 matrículas iniciais, sendo $48 \%$ para ampla concorrência, $47 \%$ para escola pública e quatro para pessoa com deficiência.

Cabe destacar que a distribuição das vagas desiguais por cotas orienta-se pela Lei ํo $12.711 / 2012$. Ela estabelece que a reserva de vagas para pretos, pardos e indígenas esteja no mínimo de acordo com a proporção dessa população no último censo. No Maranhão, era de $74 \%$ para a população negra e $0,6 \%$ para indígena. Além disso, a partir do ano de 2013, a instituição extinguiu o Comitê de Validação de Matrículas e adotou o critério de autodeclaração dos candidatos do Sisu, descartando as características fenotípicas para a ocupação das vagas reservadas à população negra. Assim, a prevalência da origem afrodescendente reforça a hipótese da desigualdade maximamente mantida, uma vez que não é mais assegurado o acesso à educação superior da população fenotipicamente negra.

$\mathrm{Na}$ tabela 2, apresenta-se a movimentação acadêmica dos estudantes de Medicina com ingresso nos anos de 2010, 2013 e 2016, por cota e pela situação acadêmica vigente no mês de junho de 2018. Após a opção pelo Sisu, as regras de entrada nos cursos de graduação se modificaram na instituição, assim como os resultados da movimentação acadêmica. 


\section{movimento \\ faculdade de educação - programa de pós-graduação em educação \\ universidade federal fluminense \\ issn 2359-3296 \\ ano 5 número 9 - 2018}

No ingresso do curso de Medicina em 2010, registrou-se um total de 102 matrículas, com 18 cancelamentos (18\%) e 84 conclusões (82\%). Vale informar que havia registro de cancelamentos e de insucessos anteriormente não observados. Apesar disso, os resultados numéricos são bastante positivos se comparados com outros cursos da IFES. Os cancelamentos foram distribuídos da seguinte maneira: $15 \%$ dos ingressantes de ampla concorrência e $41 \%$ dos estudantes de escola pública.

\begin{tabular}{|c|c|c|c|c|c|c|c|c|c|c|c|c|c|c|c|}
\hline \multirow{2}{*}{ cotas } & \multicolumn{5}{|c|}{2010} & \multicolumn{5}{|c|}{2013} & \multicolumn{5}{|c|}{2016} \\
\hline & Mat. & Ativo & Trancado & Cancelado & Formado & Mat. & Ativo & Trancado & Cancelado & Formado & Mat. & Ativo & Trancado & Cancelado & Formado \\
\hline Ampla Concorrência & 69 & 0 & 0 & 11 & 58 & 50 & 41 & 0 & 9 & 0 & 48 & 43 & 0 & 5 & 0 \\
\hline $\begin{array}{l}\text { Pretos, Pardos e } \\
\text { Indigenas (PPIs) } \\
\text { oriundos de escol as } \\
\text { públicas, com renda } \\
\text { familiar de até um } \\
\text { salário míni mo e } \\
\text { meio } \\
\end{array}$ & & & & & & 20 & 18 & 0 & 2 & 0 & 19 & 18 & 1 & 0 & 0 \\
\hline $\begin{array}{l}\text { Pretos, Pardose } \\
\text { Indígenas (PPIs) } \\
\text { oriundos de escolas } \\
\text { públicas, com renda } \\
\text { familiar superior a } \\
\text { um salário mínimo e } \\
\text { meio }\end{array}$ & 15 & 0 & 0 & 0 & 15 & 20 & 13 & 0 & 7 & 0 & 20 & 17 & 3 & 0 & 0 \\
\hline $\begin{array}{l}\text { Estudantes oriundos } \\
\text { de escolas públicas, } \\
\text { com renda familiar } \\
\text { deaté um salário } \\
\text { mínimo e meio }\end{array}$ & & & & & & 7 & 5 & 0 & 2 & 0 & 6 & 5 & 0 & 1 & 0 \\
\hline $\begin{array}{l}\text { Estudantes oriundos } \\
\text { de escolas públicas, } \\
\text { com renda familiar } \\
\text { superior a um } \\
\text { salário míni mo e } \\
\text { meio. }\end{array}$ & 17 & 0 & 0 & 7 & 10 & 5 & 5 & 0 & 0 & 0 & 4 & 4 & 0 & 0 & 0 \\
\hline Deficientes & 1 & 0 & 0 & 0 & 1 & 1 & 1 & 0 & 0 & 0 & 2 & 2 & 0 & 0 & 0 \\
\hline Total & 102 & 0 & 0 & 18 & 84 & 103 & 83 & 0 & 20 & 0 & 99 & 89 & 4 & 6 & 0 \\
\hline
\end{tabular}

Tabela 2: Movimentação Acadêmica na Medicina por ingresso/ano. Fonte: SIGAA, IFES, jun. 2018.

Em 2013, o curso de Medicina registrou-se um total de 103 matrículas: 83 ainda ativas (81\%), 20 canceladas (19\%). Nessas últimas, 18\% eram oriundas da ampla concorrência, 35\% da de negros e índios com renda superior a 1,5 salários mínimos (SM), $28,6 \%$ de escola pública com até $1,5 \mathrm{SM}$ e $10 \%$ de negros e indígenas até 1,5 SM. Em 2016, houve 99 matrículas iniciais: 89 ativas, 4 trancadas e 6 canceladas ( 5 na categoria ampla concorrência e 1 de estudante de escola pública com renda familiar de até 1,5 SM). 


\section{movimento \\ faculdade de educação - programa de pós-graduação em educação \\ universidade federal fluminense \\ issn 2359-3296 \\ ano 5 número 9 - 2018}

Ademais, o movimento acadêmico dos ingressantes em 2011 - devem ter feito ENADE em 2016 - registra matrícula inicial de 107 alunos: apenas 77 concluíram o curso (equivalente a 72\%), 3 ainda estão ativos (sendo 2 de ampla concorrência e um de escola pública) e 27 cancelaram (25\% de ingressantes). Na distribuição por categoria de ingresso, verifica-se que, na ampla concorrência, ingressaram 77: há dois ainda ativos, 18 cancelaram (23\%) e 57 concluíram. Na categoria negro, 11 foram matriculados: 2 cancelaram (18\%) e 9 concluíram. Na indígena, 1 ingressou e concluiu. Na de escola pública, 16 ingressaram: 1 está ativo, 6 cancelaram $(37,5 \%)$ e 9 concluíram. Na de pessoa com deficiência, 2 ingressaram: 1 cancelou (50\%) e 1 concluiu. Os cancelamentos ocorreram em 16,7\% dos ingressantes de escola pública com renda até $1,5 \mathrm{SM}$ e $10 \%$ de ampla concorrência.

Essas evidências no curso de Medicina permitem concluir uma tendência à estratificação educacional vertical e horizontal. A primeira concretiza-se no ingresso do curso na passagem do ciclo de escolarização, quer pela ampliação das vagas da ampla concorrência, quer pela não garantia de características fenotípicas ou pela exclusão por cancelamento pós ingresso em razão de questões econômicas e culturais. A horizontal efetiva-se pelas oportunidades e pelas condições materiais, laboratoriais e tecnológicas de estudos acadêmicos, face a facilidades de financiamentos oficiais e privados, sem descartar também a herança cultural. Cabe destacar que o fator socioeconômico está presente na categoria escola pública antes e depois da Lei de 2012, havendo registro de percentual maior de cancelamento de discentes.

Por sua vez, a tabela 3 sintetiza a movimentação acadêmica pós Sisu em Serviço Social, considerando os anos de ingresso 2010, 2013 e 2016. Há nela sinais empíricos da diferenciação em relação ao outro curso. No primeiro 


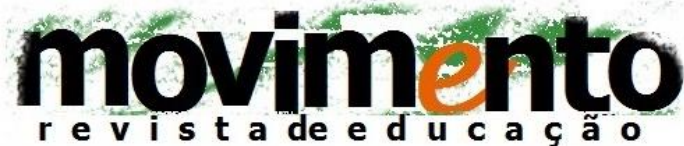 \\ faculdade de educação - programa de pós-graduação em educação \\ universidade federal fluminense \\ issn 2359-3296 \\ ano 5 número 9 - 2018}

ingresso pelo Sistema Unificado, em 2010, Serviço Social registrou um total de 82 matrículas: tendo 6 matrículas ativas (7\%), 43 cancelamentos (52\%) e 33 conclusões (40\%). Em 2013, apresentou um total de 84 ingressantes, sendo 26 discentes ativos (31\%), 5 trancados (6\%), 45 cancelados (54\%) e apenas 8 conclusões (9,5\%). Ressalta-se que os concluintes deveriam ter se formado em 2016, no entanto, ocorreram problemas de retenção no percurso acadêmico para além do tempo médio regular dessa graduação. Ainda registra-se em 2016 um total de 85 matrículas iniciais, sendo 50 ativas (59\%), 14 trancadas (16\%) e 21 canceladas (25\%), não havendo tempo de conclusões.

\begin{tabular}{|c|c|c|c|c|c|c|c|c|c|c|c|c|c|c|c|}
\hline \multirow{2}{*}{ Cotas } & \multicolumn{5}{|c|}{2010} & \multicolumn{5}{|c|}{2013} & \multicolumn{5}{|c|}{2016} \\
\hline & Mat. & Atlwo & Trancado & Cancelado & Formado & Mat. & Atlwo & Trancad o & Cancelado & Formado & Mat. & Atlwo & Trancado & Cancelado & Formado \\
\hline Ampla Concorréncia & 41 & 2 & 0 & 25 & 14 & 39 & 12 & 0 & 23 & 4 & 41 & 22 & 7 & 12 & 0 \\
\hline $\begin{array}{l}\text { Pretos, Pardos e } \\
\text { Indlgenas (PPIs) } \\
\text { oriundos de escolas } \\
\text { públicas, com renda } \\
\text { familiar de até um } \\
\text { salário minimo e } \\
\text { meio } \\
\end{array}$ & \multirow[b]{2}{*}{20} & \multirow[b]{2}{*}{1} & \multirow[b]{2}{*}{0} & \multirow[b]{2}{*}{7} & \multirow[b]{2}{*}{12} & 16 & 4 & 0 & 12 & 0 & 16 & 10 & 1 & 5 & 0 \\
\hline $\begin{array}{l}\text { Pretos, Pardos e } \\
\text { Indlgenas (PPIs) } \\
\text { oriundos de escolas } \\
\text { públicas, com renda } \\
\text { familiar superior a } \\
\text { um salário mínimo e } \\
\text { meio }\end{array}$ & & & & & & 18 & 6 & 3 & 6 & 3 & 16 & 11 & 2 & 3 & 0 \\
\hline $\begin{array}{l}\text { Estudantes oriundos } \\
\text { de escolas públicas, } \\
\text { com renda familiar } \\
\text { de até um salário } \\
\text { mínimo e meio }\end{array}$ & \multirow[b]{2}{*}{20} & \multirow[b]{2}{*}{3} & \multirow[b]{2}{*}{0} & \multirow[b]{2}{*}{11} & \multirow[b]{2}{*}{6} & 5 & 2 & 0 & 2 & 1 & 4 & 3 & 1 & 0 & 0 \\
\hline $\begin{array}{l}\text { Estudantes oriundos } \\
\text { de escolas públicas, } \\
\text { com renda familiar } \\
\text { superior a um } \\
\text { salário mínimo e } \\
\text { meio. }\end{array}$ & & & & & & 5 & 1 & 2 & 2 & 0 & 4 & 3 & 0 & 1 & 0 \\
\hline Deficientes & 1 & 0 & 0 & 0 & 1 & 1 & 1 & 0 & 0 & 0 & 4 & 1 & 3 & 0 & 0 \\
\hline Total & 82 & 6 & 0 & 43 & 33 & 84 & 26 & 5 & 45 & 8 & 85 & 50 & 14 & 21 & 0 \\
\hline
\end{tabular}

Tabela 3: Movimentação acadêmica no Serviço Social por ingresso/ano. Fonte: Elaborada com base em dados do SIGAA, IFES, jun. 2018.

Em uma análise dos cancelamentos e do sucesso acadêmico no curso de Serviço Social, verifica-se que, em 2010, na categoria ampla concorrência, ingressaram 41 estudantes: 25 cancelaram (61\% deste total) e 14 concluíram (34\%). Na de negros, 20 matrículas iniciais: 7 cancelaram (35\%) e 12 concluíram (60\%). Na de escola pública, houve 20: 11 canceladas (55\%) e 6 


\section{$\underset{r e v i s t a d e d u c t o c s}{\operatorname{movim}}$ \\ faculdade de educação - programa de pós-graduação em educação \\ universidade federal fluminense \\ issn 2359-3296 \\ ano 5 número 9 - 2018}

formados (30\%). Existiu ainda 1 ingresso de pessoa com deficiência que concluiu o curso. Em 2013, na categoria ampla concorrência, ingressaram 39 estudantes: 23 cancelaram (59\%) e 4 concluíram (10\%). Na de negros e indígena até 1,5 SM, 16 iniciais: 12 cancelaram (75\%) e não houve conclusão. $\mathrm{Na}$ de negro e indígena com renda maior $1,5 \mathrm{SM}$, houve 18 matrículas: 3 trancados, 6 cancelados (33\%) e 3 formados (16,6\%). Na categoria com renda até 1,5 SM, houve 5 matrículas: 2 cancelados (40\%) e 1 formado (20\%). Na de renda superior a 1,5 SM, registraram-se 5 matrículas: 2 trancados, 2 cancelados (40\%) e sem conclusão. Ainda ingressou 1 pessoa com deficiência que continua com a matrícula ativa.

Em 2016, na categoria ampla concorrência, houve 41 matrículas iniciais: 12 cancelaram (29\%), 22 estão ativos e 7 trancadas (17\%). Na de negros e indígena até 1,5 SM, 16 iniciais: 10 ativos, 5 cancelaram (31\%) e 1 trancou. $\mathrm{Na}$ categoria negro e indígena com renda maior 1,5 SM, houve 16: 11 estão ativos, 2 trancados e 3 cancelados (18,8\%). Na com renda até 1,5 SM, houve 4 matrículas: 3 estão ativos e 1 trancado (25\%). Na categoria renda superior a 1,5 SM, registraram-se 4 matrículas: 3 estão ativas e 1 canceladas (25\%). Ainda ingressaram 4 pessoas com deficiência, encontrando-se $1 \mathrm{com}$ matrícula ativa e 3 trancados $(75 \%)$.

Com base na expansão de vagas na educação superior e nessa movimentação acadêmica a partir do curso de Serviço Social, pode-se afirmar que tais dados contribuem para manutenção da estratificação educacional horizontal, sinalizada na retenção de discentes para além da duração regular, nos cancelamentos por motivo de opções de cursos de maior valorização no mercado de trabalho ou na hierarquia social, especialmente na categoria ampla concorrência, além de condições materiais e tecnológicas menos favoráveis. Os cancelamentos também podem significar estratificação vertical para aqueles 


\section{movimento \\ faculdade de educação - programa de pós-graduação em educação \\ universidade federal fluminense \\ issn 2359-3296 \\ ano 5 número 9 - 2018}

que não concluem por dificuldades socioeconômicas, cabendo aqui mencionar as seguintes considerações de Almeida et al. (2012, p. 913):

[...] as taxas de abandono e de insucesso penalizam, sobretudo, os alunos provenientes dos estratos sociais mais desfavorecidos, mesmo não havendo estatísticas seguras para o demonstrar. De novo, a frequência a um curso de que não se gosta e a necessidade de conciliar os estudos com alguma forma de trabalho, mesmo que temporário [...] são fatores explicativos de uma taxa considerável de insucesso e de abandono, sobretudo junto dos alunos pertencentes aos grupos sociais mais desfavorecidos.

Segundo esses autores, existem outras implicações atinentes à transição para o ensino superior, como as dificuldades quotidianas não vivenciadas anteriormente (questões de moradia, transporte e alimentação). Do mesmo modo, ao se inserir em um novo contexto de vida, o estudante é compelido a estabelecer novas relações sociais e a encontrar grupos de suporte afetivo e social. Do ponto de vista econômico, a situação ainda pode vir a se agravar caso o aluno necessite, desde o início, encontrar meios de financiamento dos seus estudos como forma de não ter de adiar a sua formação.

\section{Perfil dos estudantes concluintes dos cursos de Medicina e Serviço Social na instituição}

A análise da estratificação educacional também considerou informações do perfil socioeconômico e cultural dos concluintes submetidos ao Enade em 2010, 2013 e 2016 desses cursos com base no questionário preenchido online na página do INEP.

A distribuição dos participantes por curso ocorreu da seguinte forma: a) Medicina, em 2010, foram 92 concluintes; em 2013, 38 e em 2016, 75; b) Serviço Social, em 2010, foram 164 concluintes; em 2013, 33; e em 2016, 57. A princípio, pressupõe-se que o ingresso desses concluintes de Medicina (curso 


\section{movimento \\ faculdade de educação - programa de pós-graduação em educação \\ universidade federal fluminense \\ issn 2359-3296 \\ ano 5 número 9 - 2018}

com duração média de 6 anos) na Instituição deveria ser na sequência 2005, 2008 e 2011, enquanto os de Serviço Social (curso de 4 anos) nos anos de 2007, de 2010 e de 2013. Sendo assim, o curso de Medicina apresenta um perfil antes da política de ações afirmativas e em dois momentos diferenciados dessa política em curso na instituição.

A seguir, apresentam-se os resultados conforme 7 quesitos do QSE/ENADE sistematizados nas tabelas abaixo e que dão conta de relevantes aspectos a serem considerados na análise da estratificação educacional como a cor/raça, a renda familiar, a situação financeira, a escolaridade do pai e da mãe, o tipo de escola cursada no ensino médio, entre outros.

A tabela 4 apresenta o perfil cor/raça, segundo o QSE/ENADE, indicando diferenças nos percentuais relativos à presença de brancos e de pretos nesses dois cursos nos três anos de Enade. Lembramos que essa presença ocorre apesar da política de ações afirmativas da instituição, com critérios de validação da matrícula da cota do negro por características fenotípicas no período de 2007 ao ingresso de 2012 e a partir de 2013 prevalecendo a autodeclaração.

\begin{tabular}{c|c|c|c|c|c|c} 
& \multicolumn{2}{|c|}{$\mathbf{2 0 1 0}$} & \multicolumn{2}{c|}{$\mathbf{2 0 1 3}$} & \multicolumn{2}{c}{$\mathbf{2 0 1 6}$} \\
\hline & Medicina & $\begin{array}{c}\text { Serviço } \\
\text { Social }\end{array}$ & Medicina & $\begin{array}{c}\text { Serviço } \\
\text { Social }\end{array}$ & Medicina & $\begin{array}{c}\text { Serviço } \\
\text { Social }\end{array}$ \\
\hline Branca & 42,7 & 22,8 & 36,8 & 23,5 & 45,3 & 21,1 \\
Preta & 6,1 & 32,9 & 18,4 & 17,6 & 14,7 & 29,8 \\
Amarela & 0,0 & 2,5 & 0,0 & 0,0 & 1,3 & 0,0 \\
Parda & 51,2 & 40,5 & 39,5 & 52,9 & 38,7 & 45,3 \\
Indígena & 0,0 & 1,3 & 5,3 & 5,9 & 0,0 & 0,0 \\
Não declarou & - & - & - & - & 0,0 & 3,5
\end{tabular}

Tabela 4: Percentual de estudantes por cor/raça. Fonte: INEP, 2018.

$\mathrm{Na}$ análise dessa tabela, percebe-se no perfil dos concluintes de Medicina de 2010 , com ingresso sem cota, a prevalência da cor parda (51,2\%), seguida por brancos $(42,7 \%)$ e reduzida presença de pretos (6,1\%). Em 2013, já havia cota racial e validação de matrícula, mas houve também maior percentual de pardos 


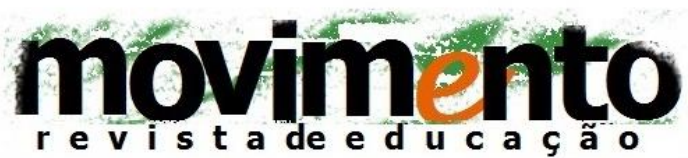 \\ faculdade de educação - programa de pós-graduação em educação \\ universidade federal fluminense \\ issn 2359-3296 \\ ano 5 número 9 - 2018}

$(39,5 \%)$, redução de brancos $(36,8 \%)$, ampliação de pretos $(18,4 \%)$ e presença de indígena. Em 2016, ainda com validação de matrícula no ingresso de cotas raciais, predomina a presença de brancos $(45,3 \%)$, pardos $(38,7 \%)$, pretos $(14,7 \%)$ e aparece a cor amarela.

No caso de Serviço Social, os concluintes dos três Enade já ingressaram com políticas de ação afirmativa, sendo que o último com aquelas prescritas pela Lei oㅜ 12.711/2012. Em 2010, entre os concluintes, havia a predominância de pardos e pretos e aproximadamente a metade do percentual de brancos da Medicina, além de presença de indígena. Em 2013, não há aumento relevante no percentual de brancos, aumenta a presença de pardos, diminui a de pretos e amplia a de indígena. Em 2016, o percentual de brancos não tem alterações relevantes e amplia-se o de pretos e o de pardos. Em síntese, pode-se afirmar que, em Medicina, os declarados negros (pretos e pardos) no QSE, na sequência dos três anos, representam os percentuais de $57,3 \%, 57,9$ e $53,4 \%$, enquanto em Serviço Social, a 73,4\%, 70,5\% e 75,1\%.

Essas evidências permitem afirmar a existência de estratificação educacional horizontal relacionada à hipótese da desigualdade maximamente efetivada, considerando que historicamente os negros - em sua maioria -encontram-se em condições culturais e socioeconômicas desprivilegiadas e terminam ingressando em cursos com menor barreira seletiva e de menor valorização na hierarquia social.

A persistência dessas desigualdades relacionadas à cor/raça é também verificada após a implantação de políticas que buscam conciliar a expansão de vagas com a democratização do acesso por meio do aumento da participação relativa de minorias sociais. Ribeiro e Schlegel (2015) argumentam que, apesar de uma maior participação das mulheres e dos PPIs no ensino superior nos 


\section{movimento \\ faculdade de educação - programa de pós-graduação em educação \\ universidade federal fluminense \\ issn 2359-3296 \\ ano 5 número 9 - 2018}

últimos anos, essa inclusão não representou acesso igualitário a todas as carreiras universitárias, tendo sido mais intensa em áreas menos valorizadas pelo mercado de trabalho. Para os autores, superar esse problema torna-se relevante para que as políticas voltadas para a igualdade de oportunidades no ensino superior mantenham seu alvo e alcancem efetividade.

O QSE/ENADE apresenta também informações sobre renda familiar dos concluintes, conforme tabela 5 .

\begin{tabular}{c|c|c|c|c|c|c} 
& \multicolumn{2}{|c|}{2010} & \multicolumn{2}{c|}{$\mathbf{2 0 1 3}$} & \multicolumn{2}{c}{2016} \\
\hline & Medicina & $\begin{array}{c}\text { Serviço } \\
\text { Social }\end{array}$ & Medicina & $\begin{array}{c}\text { Serviço } \\
\text { Social }\end{array}$ & Medicina & $\begin{array}{c}\text { Serviço } \\
\text { Social }\end{array}$ \\
\hline Nenhuma & 7,3 & 6,3 & - & - & - & - \\
Até 1,5 s.m & 1,2 & 11,4 & 2,6 & 29,4 & 6,7 & 22,8 \\
De 1,5 a 3 s.m & 1,2 & 31,6 & 21,1 & 23,5 & 12,0 & 33,3 \\
\hline De 3 a 4,5 s.m & 11,0 & 20,3 & 13,2 & 23,5 & 16,0 & 14,0 \\
De 4,5 até 6 s.m & 7,3 & 12,7 & 15,8 & 23,5 & 16,0 & 21,1 \\
De 6 até 10 s.m & 18,3 & 15,2 & 28,9 & 0,0 & 21,3 & 7,0 \\
De 10 até 30 s.m & 45,1 & 2,5 & 10,5 & 0,0 & 25,3 & 1,8 \\
Acima de 30 s.m & 8,5 & 0,0 & 7,9 & 0,0 & 2,7 & 0,0
\end{tabular}

Tabela 5: Percentual de estudantes por renda familiar. Fonte: INEP, 2018.

Em relação à renda familiar, observa-se que, no ano de 2010, 45,1\% dos concluintes de Medicina possuíam renda familiar entre 10 e 30 salários mínimos. Percentual que diminuiu para 10,5\% em 2013 e aumentou para 25,3\% em 2016. Em Serviço Social, por sua vez, a faixa de renda com maior frequência entre os concluintes foi de 1,5 a 3 salários mínimos, correspondendo a 31,6\% em 2010, com queda para 23,5\% em 2013 (ano em que foi maior o percentual da faixa de renda de até 1,5 salários mínimos) e aumentando para 33,3\% em 2016. No curso de Medicina, em 2010, essa faixa de renda familiar de 1,5 a 3 salários mínimos era de apenas 1,2\% o percentual, elevou-se para $21,1 \%$ em 2013 e reduziu para 16\% em 2016. No entanto, percebe-se a presença de estudantes que representam faixas de renda inferiores a 6 salários mínimos a partir de 2013, o que significa a inclusão de discentes dos extratos sociais mais baixos. 


\section{movimento \\ faculdade de educação - programa de pós-graduação em educação \\ universidade federal fluminense \\ issn 2359-3296 \\ ano 5 número 9 - 2018}

De acordo com a tabela 6 , nos três anos, tanto os concluintes de Medicina como os de Serviço Social não possuem renda própria em sua maioria e seus gastos são financiados pela família ou por outras pessoas. Essa informação fica ainda mais evidente no curso de Medicina, cujo percentual era de $84,1 \%$ em 2010, subindo para 89,5\% em 2013 e mantendo-se em 2016 com o percentual de $89,3 \%$.

\begin{tabular}{|c|c|c|c|c|c|c|}
\hline & \multicolumn{2}{|c|}{2010} & \multicolumn{2}{|c|}{2013} & \multicolumn{2}{|c|}{2016} \\
\hline & Medicina & $\begin{array}{l}\text { Serviço } \\
\text { Social }\end{array}$ & Medicina & $\begin{array}{l}\text { Serviço } \\
\text { Social }\end{array}$ & Medicina & $\begin{array}{c}\text { Serviço } \\
\text { Social }\end{array}$ \\
\hline $\begin{array}{l}\text { Não tem renda e gastos são } \\
\text { financiados por programas } \\
\text { governamentais. }\end{array}$ & - & - & 0,0 & 11,8 & 4,0 & 1,8 \\
\hline $\begin{array}{l}\text { Não tem renda e gastos são } \\
\text { financiados pela família ou } \\
\text { por outras pessoas. }\end{array}$ & 84,1 & 68,4 & 89,5 & 70,6 & 89,3 & 52,6 \\
\hline $\begin{array}{l}\text { Tem renda, mas recebe } \\
\text { ajuda da família ou de } \\
\text { outras pessoas. }\end{array}$ & 9,8 & 25,3 & 5,3 & 11,8 & 6,7 & 24,6 \\
\hline $\begin{array}{l}\text { Tem renda e não precisa de } \\
\text { ajuda. }\end{array}$ & 3,7 & 0,0 & 2,6 & 0,0 & 0,0 & 1,8 \\
\hline $\begin{array}{l}\text { Tem renda e contribui com } \\
\text { o sustento da família. }\end{array}$ & 1,2 & 5,1 & 0,0 & 5,9 & 0,0 & 14,0 \\
\hline $\begin{array}{l}\text { É o principal responsável } \\
\text { pelo sustento da família. }\end{array}$ & 1,2 & 1,3 & 2,6 & 0,0 & 0,0 & 5,3 \\
\hline
\end{tabular}

Tabela 6: Percentual de estudantes por situação financeira. Fonte: INEP, 2018.

Porém, em Serviço Social, apesar desse registro de percentual elevado, ocorre também a presença de concluintes que possuem renda própria ou contribuem para o sustento da família. Assim, em 2013, 11,8\% deles não tinham renda própria, mas tinham gastos financiados por programas governamentais, enquanto em 2016 houve aumento do percentual de renda própria complementar e de contribuição para o sustento da família (14\%), além de alunos que são a principal fonte de sustento familiar $(5,3 \%)$.

As variáveis educacionais do perfil dos concluintes encontram-se nas tabelas 7 a 9 e complementam informações sobre a estratificação educacional em Medicina e em Serviço Social. A tabela 7 trata da escolaridade dos pais, 


\section{movimento \\ faculdade de educação - programa de pós-graduação em educação \\ universidade federal fluminense \\ issn 2359-3296 \\ ano 5 número 9 - 2018}

indicando a prevalência de pais com educação superior na Medicina enquanto predominam pais com ensino médio no Serviço Social.

\begin{tabular}{|c|c|c|c|c|c|c|}
\hline & \multicolumn{2}{|c|}{2010} & \multicolumn{2}{|c|}{2013} & \multicolumn{2}{|c|}{2016} \\
\hline & Medicina & $\begin{array}{l}\text { Serviço } \\
\text { Social }\end{array}$ & Medicina & $\begin{array}{l}\text { Serviço } \\
\text { Social }\end{array}$ & Medicina & $\begin{array}{l}\text { Serviço } \\
\text { Social }\end{array}$ \\
\hline Nenhuma. & 0,0 & 5,1 & 0,0 & 12,5 & 2,7 & 3,5 \\
\hline $\begin{array}{l}\text { Ensino fundamental: do } 1^{\circ} \\
\text { ao } 5^{\circ} \text { ano ( } 1^{\mathrm{a}} \text { a } 4^{\mathrm{a}} \text { série). }\end{array}$ & 8,5 & 13,9 & 2,7 & 18,8 & 5,3 & 19,3 \\
\hline $\begin{array}{l}\text { Ensino fundamental: do } 6^{\circ} \\
\text { ao } 9^{\circ} \text { ano ( } 5^{\mathrm{a}} \text { a } 8^{\mathrm{a}} \text { série). }\end{array}$ & 6,1 & 13,9 & 5,4 & 6,3 & 6,7 & 10,5 \\
\hline Ensino médio. & 25,6 & 48,1 & 40,5 & 56,3 & 29,3 & 56,1 \\
\hline $\begin{array}{l}\text { Ensino superior - } \\
\text { Graduação. }\end{array}$ & 52,4 & 16,5 & 43,2 & 6,3 & 37,3 & 5,3 \\
\hline Pós-graduação. & 7,3 & 1,3 & 8,1 & 0,0 & 18,7 & 5,3 \\
\hline
\end{tabular}

Tabela 7: Percentual de estudantes por escolaridade dos pais. Fonte: INEP 2018.

$\mathrm{Na}$ Medicina, em 2010, ocorre a presença de 52,4\% dos pais com educação superior e $25,6 \%$ com ensino médio. Há redução de pais com nível superior em 2013, com $43,2 \%$, e em 2016, com $37,3 \%$. Na sequência dos anos, os pais com ensino médio aumentaram para 40,5\% em 2013 e diminuíram para 29,3\% em 2016, ano em que houve $18,7 \%$ de pais com pós-graduação. Em Serviço Social, apesar de já reduzida a presença de pais com educação superior (16,5\%), desde 2010, houve queda em 2013 para 6,3\% e em 2016 para 5,3\%, tendo esse mesmo percentual na pós-graduação. Neste curso, houve aumento de pais de nível médio, sendo o percentual de $48,1 \%$ em 2010 , de $56,3 \%$ em 2013 e 56,1\% no último ano. Além disso, registra pais com menor escolarização que se amplia na sequência dos anos, tais como a primeira e/ou a segunda etapas do ensino fundamental, havendo também aqueles sem escolarização. Em Medicina, o registro de pais sem escolarização ocorre apenas em 2016. Perfil similar registra-se quanto à escolaridade das mães, conforme mostra a tabela 8 .

\begin{tabular}{|c|c|c|c|c|c|c|}
\hline & \multicolumn{2}{|c|}{2010} & \multicolumn{2}{|c|}{2013} & \multicolumn{2}{|c|}{2016} \\
\hline & Medicina & $\begin{array}{c}\text { Serviço } \\
\text { Social }\end{array}$ & Medicina & $\begin{array}{c}\text { Serviço } \\
\text { Social }\end{array}$ & Medicina & $\begin{array}{l}\text { Serviço } \\
\text { Social }\end{array}$ \\
\hline Nenhuma. & 0,0 & 2,5 & 0,0 & 5,9 & 0,0 & 3,5 \\
\hline $\begin{array}{l}\text { Ensino fundamental: do } 1^{\circ} \\
\text { ao } 5^{\circ} \text { ano ( } 1^{\mathrm{a}} \text { a } 4^{\mathrm{a}} \text { série). }\end{array}$ & 2,4 & 17,7 & 2,6 & 23,5 & 5,3 & 12,3 \\
\hline
\end{tabular}




\section{movimento \\ faculdade de educação - programa de pós-graduação em educação \\ universidade federal fluminense \\ issn 2359-3296 \\ ano 5 número 9 - 2018}

\begin{tabular}{|c|c|c|c|c|c|c|}
\hline $\begin{array}{l}\text { Ensino fundamental: do } 6^{\circ} \\
\text { ao } 9^{\circ} \text { ano }\left(5^{\mathrm{a}} \text { a } 8^{\mathrm{a}} \text { série). }\right.\end{array}$ & 6,1 & 10,1 & 2,6 & 5,9 & 5,3 & 15,8 \\
\hline Ensino médio. & 32,9 & 55,7 & 50,0 & 41,2 & 28,0 & 45,6 \\
\hline $\begin{array}{l}\text { Ensino superior } \\
\text { Graduação. }\end{array}$ & 47,6 & 7,6 & 28,9 & 23,5 & 33,3 & 15,8 \\
\hline Pós-graduação. & 11,0 & 6,3 & 15,8 & 0,0 & 28,0 & 7,0 \\
\hline
\end{tabular}

$\mathrm{Na}$ Medicina, predomina a formação das mães com nível superior (graduação e pós-graduação) em 2010 e 2016, havendo um declínio em 2013, com um percentual maior de ensino médio. Outro destaque é o percentual de mães com pós-graduação, com aumento gradual nos anos em que o QSE foi aplicado: 11\% em 2010, 15,8\% em 2013 e 28\% em 2016. No curso de Serviço Social, a predominância do nível de formação das mães é o ensino médio, havendo forte presença da primeira etapa do ensino fundamental com um declínio em 2016. Quanto ao nível superior, apresentou baixa frequência em 2010, aumentou em 2013 e declinou em 2016, embora haja registro de pós-graduação.

Esses resultados apontam para a existência de diferenças significativas - em termos socioeconômicos e de capital cultural familiar - entre os concluintes de Medicina e Serviço Social da IFES em estudo, o que evidencia o aprofundamento das desigualdades de oportunidades e influencia o sucesso escolar. Constituem ainda um reflexo do que tem ocorrido no contexto brasileiro nos últimos cinquenta anos. Conforme estudos de Ribeiro et al. (2015), os efeitos da escolaridade da mãe, da renda per capita familiar e das características sociais do ambiente familiar evidenciam que a origem social dos jovens brasileiros teve forte impacto na sua trajetória de ensino, tanto em termos de acesso quanto de progressão no sistema educacional. Se nos anos 1960, 1970 e 1980 essas barreiras se interpunham aos discentes no início das suas trajetórias estudantis, a partir da década de 1990, elas foram se deslocando para os níveis mais altos da escolarização. Dessa forma, houve uma diminuição da desigualdade de oportunidades nos níveis básicos, persistência no nível médio e aumento no nível superior. 


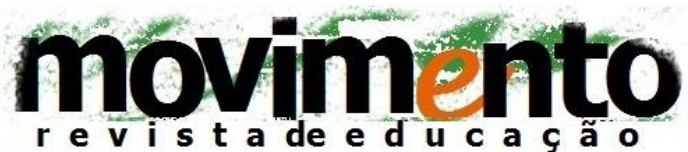 \\ faculdade de educação - programa de pós-graduação em educação \\ universidade federal fluminense \\ issn 2359-3296 \\ ano 5 número 9 - 2018}

Para Mont'Alvão (2016), diferenciações qualitativas no ensino superior, como as observadas nas tabelas 5 a 8 , correspondem a escolhas condicionadas socialmente, de modo que estudantes dos estratos socioeconômicos mais altos têm vantagens de acesso às instituições mais prestigiadas e aos campos educacionais com maior retorno posterior.

Em termos institucionais, o autor menciona que as hierarquias internas demarcam diferenciais qualitativos quanto ao prestígio $e$ ao retorno socioeconômico por campos educacionais. Isso implica maior seletividade no acesso a cursos com maiores retornos, como Medicina, Engenharias, Ciências Aplicadas - exatas e naturais - e Direito. Por outro lado, as Ciências Humanas e Sociais constituem as áreas com menos barreiras na seleção.

Essa seletividade é observada principalmente em termos de classes sociais de origem. Parte do seu efeito está relacionado ao desempenho acadêmico: estudantes pertencentes às classes sociais mais altas apresentam maior probabilidade de sucesso tanto no acesso quanto na conclusão dos cursos de maior prestígio.

Acrescenta-se a esse aspecto o que a tabela 9 informa sobre a natureza da escola frequentada no ensino médio. É fácil perceber, como nas tabelas anteriores, as diferenças na origem escolar dos concluintes dos dois cursos. $\mathrm{Na}$ Medicina, nos três anos, os concluintes cursaram o ensino médio em escola particular (81,7\% em 2010,71,1\% em 2013, e 73,3\% em 2016), apesar do tempo do ingresso já haver políticas afirmativas na IFES, com exceção para os questionados em 2010. Ainda assim, percebe-se a inclusão de concluintes da rede pública com as seguintes oscilações: 7,3\% em 2010, 21,1\% em 2013 e 17,3\% em 2016. Em Serviço Social, apesar de pequenas variações, há certo equilíbrio nos números entre público e privado. 


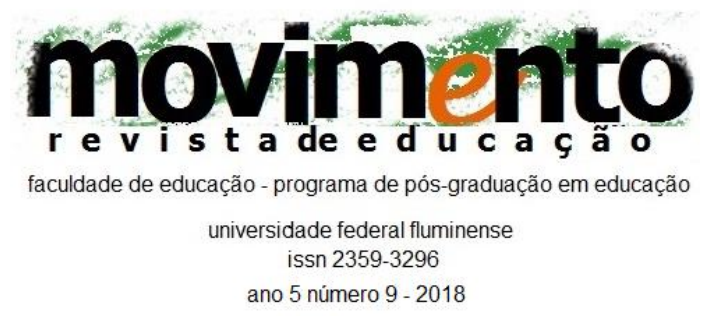

\begin{tabular}{|c|c|c|c|c|c|c|}
\hline & \multicolumn{2}{|c|}{2010} & \multicolumn{2}{|c|}{2013} & \multicolumn{2}{|c|}{2016} \\
\hline & Medicina & \begin{tabular}{|c|} 
Serviço \\
Social
\end{tabular} & Medicina & $\begin{array}{l}\text { Serviço } \\
\text { Social }\end{array}$ & Medicina & $\begin{array}{r}\text { Serviço } \\
\text { Social }\end{array}$ \\
\hline Todo em escola pública. & 7,3 & 48,1 & 21,1 & 52,9 & 17,3 & 49,1 \\
\hline $\begin{array}{l}\text { Todo em escola privada } \\
\text { (particular). }\end{array}$ & 81,7 & 43,0 & 71,1 & 47,1 & 73,3 & 38,6 \\
\hline Todo no exterior. & - & - & - & - & 0,0 & 0,0 \\
\hline $\begin{array}{l}\text { A maior parte em escola } \\
\text { pública. }\end{array}$ & 3,7 & 1,3 & 5,3 & 0,0 & 1,3 & 5,3 \\
\hline $\begin{array}{l}\text { A maior parte em escola } \\
\text { privada (particular). }\end{array}$ & 6,1 & 3,8 & 2,6 & 0,0 & 5,3 & 7,0 \\
\hline $\begin{array}{l}\text { Parte no Brasil e parte no } \\
\text { exterior. }\end{array}$ & - & - & - & - & 2,7 & 0,0 \\
\hline $\begin{array}{l}\text { Metade em escola pública e } \\
\text { metade em escola privada } \\
\text { (particular) }\end{array}$ & 1,2 & 2,5 & - & - & - & - \\
\hline
\end{tabular}

Tabela 9: Percentual de estudantes por tipo de escola cursada no ensino médio.Fonte: INEP, 2018.

Por último, a tabela 10 apresenta os dados sobre o ingresso pela via das políticas afirmativas. No entanto, essa questão só foi incluída no instrumento em 2013 e traz complexidade para a interpretação, considerando que os dois cursos têm duração diferenciada (seis ou quatro anos). Dessa maneira, as duas graduações possuíam critérios diversos no ingresso.

Assim, os concluintes da Medicina em 2013 ingressaram via PSG (25\% das vagas) ou Vestibular (70\% das vagas): neste $50 \%$ das vagas para universal e $25 \%$ para cada uma das categorias (racial ou escola pública). Portanto, os percentuais das respostas relacionam-se com a política implementada e parecem indicar maior diversidade na composição social do alunado.

\begin{tabular}{l|c|c|c|c|c|c} 
& \multicolumn{2}{|c|}{2010} & \multicolumn{2}{c|}{2013} & \multicolumn{2}{c}{2016} \\
\hline & Medicina & $\begin{array}{c}\text { Serviço } \\
\text { Social }\end{array}$ & Medicina & $\begin{array}{c}\text { Serviço } \\
\text { Social }\end{array}$ & Medicina & $\begin{array}{c}\text { Serviço } \\
\text { Social }\end{array}$ \\
\hline Não. & - & - & 55,3 & 47,1 & 72,0 & 63,2
\end{tabular}




\section{movimento \\ faculdade de educação - programa de pós-graduação em educação \\ universidade federal fluminense \\ issn 2359-3296 \\ ano 5 número 9 - 2018}

\begin{tabular}{|c|c|c|c|c|c|c|}
\hline Sim, por critério étnico-racial. & - & - & 21,1 & 23,5 & 9,3 & 15,8 \\
\hline Sim, por critério de renda. & - & - & 0,0 & 0,0 & 0,0 & 0,0 \\
\hline $\begin{array}{l}\text { Sim, por ter estudado em } \\
\text { escola pública ou particular } \\
\text { com bolsa de estudos. }\end{array}$ & - & - & 21,1 & 29,4 & 13,3 & 14,0 \\
\hline $\begin{array}{l}\text { Sim, por sistema que combina } \\
\text { dois ou mais critérios } \\
\text { anteriores. }\end{array}$ & - & - & 2,6 & 0,0 & 4,0 & 3,5 \\
\hline $\begin{array}{l}\text { Sim, por sistema diferente dos } \\
\text { anteriores. }\end{array}$ & - & - & 0,0 & 0,0 & 1,3 & 3,5 \\
\hline
\end{tabular}

Tabela 10: Percentual de estudantes segundo ingresso por políticas de ação afirmativa ou inclusão social. Fonte: INEP, 2018.

Por sua vez, os concluintes de Serviço Social em 2013 e os de Medicina em 2016 ingressaram pelo Sisu em 2010 e em 2011 respectivamente, com ajustamentos nas políticas afirmativas pela extinção do PSG, mantendo-se as cotas para ampla concorrência, escola pública, negro e vagas especiais para deficientes e indígenas. Vale lembrar que ainda existia uma Comissão de Validação de matrículas por critérios fenotípicos e, quando algum candidato não era aceito, as vagas retornavam para a ampla concorrência. Isso explica o alto percentual em Medicina de concluintes em 2016 que não ingressaram por ações afirmativas, podendo significar a admissão de camadas sociais mais privilegiadas.

Cabe ainda destacar que Serviço Social manteve-se em 2013 de acordo com os critérios do ingresso em 2010, diversificando mais a composição social do curso. Porém, as respostas dos concluintes de 2016 indicam um percentual alto de alunos que não ingressaram em 2013 por cotas, provavelmente em razão de cancelamentos no percurso acadêmico ou pelo retorno de vagas para ampla concorrência.

Apesar de um avanço na superação do elevado grau de elitismo verificado no ensino superior, Ribeiro e Schlegel (2015) afirmam que as mudanças ocorridas ainda não foram capazes de superar desigualdades na conclusão e na obtenção de títulos nas diferentes carreiras, de modo que ainda se verifica forte 


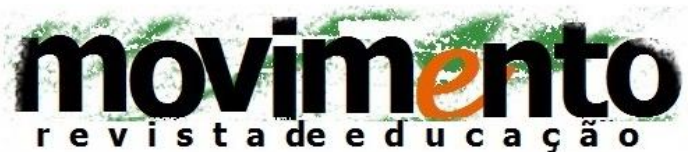 \\ faculdade de educação - programa de pós-graduação em educação \\ universidade federal fluminense \\ issn 2359-3296 \\ ano 5 número 9 - 2018}

estratificação horizontal no sistema de ensino superior no Brasil. Isso pode ser percebido no presente estudo, na medida em que as diferenças significativas são verificadas entre os perfis socioeconômicos e culturais dos concluintes dos cursos de Medicina e de Serviço Social da IFES analisada.

\section{Considerações Finais}

A estratificação educacional relaciona-se com a influência da origem socioeconômica e cultural na reprodução das desigualdades na posse de instrumentos de poder e de bens materiais e simbólicos. Isso tem implicações negativas para as políticas sociais que promovem certas mobilidades na hierarquia das posições na sociedade.

A educação superior, entendida como bem público, coloca-se como estratégia de ascensão social e ao mesmo tempo atende aos interesses do desenvolvimento econômico. Além disso, prepara os sujeitos para exercerem diferentes papéis sociais. Com a visão da universidade como instrumento de poder e de posição social, os grupos com estrutura familiar de posse de instrumentos políticos e de bens econômicos e culturais buscam manter seus privilégios e suas posições nos níveis mais elevados da hierarquia social. Eles criam barreiras educacionais ao acesso ao ensino superior diversificado. Esse movimento reproduz a estratificação educacional na transição do ensino médio para o superior e no interior desse nível de ensino. Tudo por meio da posição de prestígio social dos tipos institucionais e dos cursos, das condições materiais e das simbólicas no percurso acadêmico.

A pesquisa nos cursos de Medicina e de Serviço Social da IFES indicou a existência da estratificação educacional neles nas dimensões vertical (transição de níveis educacionais) e horizontal (hierarquias internas de prestígio e 


\section{movimento \\ faculdade de educação - programa de pós-graduação em educação \\ universidade federal fluminense \\ issn 2359-3296 \\ ano 5 número 9 - 2018}

qualidade). No primeiro, a estratificação vertical revela-se pela prevalência da cor branca ou da autodeclaração parda, do nível de renda, do capital cultural da família, do ensino médio em escola particular, do número de ingressos na ampla concorrência e das exclusões de ingressantes de categorias sociais menos privilegiadas. No outro, evidencia-se na tendência de homogeneização do acesso por grupos sociais menos favorecidos pela cor/raça, pela renda familiar, pela escolarização da família (capital cultural), pelo ensino médio em escola pública e pelas exclusões educacionais. Por sua vez, a estratificação horizontal marca distinções pelo status dos cursos, pelas pontuações do ENEM para acesso, pelas retenções no curso, pelo sucesso acadêmico e pela qualidade de condições materiais, laboratoriais e tecnológicas acessíveis durante a formação.

Tais evidências reclamam por políticas sociais que rompam as barreiras educacionais na perspectiva de uma educação superior mais inclusiva de fato.

\section{Referências}

ALMEIDA, Leandro et al. Democratização do acesso e do sucesso no ensino superior: uma reflexão a partir das realidades de Portugal e do Brasil. Avaliação, Campinas; Sorocaba, v. 17, n. 3, p.899-920, nov. 2012.

BRASIL. INEP. ENADE 2010: Relatório de curso Medicina UFMA/São Luís. 2010. Disponível em: <http://enadeies.inep.gov.br/enadeles/enadeResultado/>. Acesso em: 15 abr. 2018.

. ENADE 2010: Relatório de curso Serviço Social UFMA/São Luís.

2010. Disponível em: <http://enadeies.inep.gov.br/enadeles/enadeResultado/>. Acesso em: 15 abr. 2018.

ENADE 2013: Relatório de curso Medicina UFMA/São Luís. 2013.

Disponível em: <http://enadeies.inep.gov.br/enadeles/enadeResultado/>. Acesso em: 15 abr. 2018. 


\section{movimento \\ faculdade de educação - programa de pós-graduação em educação \\ universidade federal fluminense \\ issn 2359-3296 \\ ano 5 número 9 - 2018}

ENADE 2013: Relatório de curso Serviço Social UFMA/São Luís.

2013. Disponível em: <http://enadeies.inep.gov.br/enadeles/enadeResultado/>. Acesso em: 15 abr. 2018.

ENADE 2016: Relatório de curso Medicina UFMA/São Luís. 2016.

Disponível em: <http://enadeies.inep.gov.br/enadeles/enadeResultado/>. Acesso em: 15 abr. 2018.

ENADE 2016: Relatório de curso Serviço Social UFMA/São Luís.

2016. Disponível em: <http://enadeies.inep.gov.br/enadeles/enadeResultado/>. Acesso em: 15 abr. 2018.

HOUT, Michael. Maximally Maintained Inequality and Essentially Maintained Inequality: Crossnational Comparisons. Sociological Theory and Methods Symposium. 2006, Vol. 21, p. 237-252.

MONT'ALVÃO, Arnaldo. A dimensão vertical e horizontal da estratificação educacional. Teoria e Cultura. Revista da Pós-Graduação em Ciências Sociais - UFJF, v. 11, n. 1, p.13-20, jan./jun. 2016.

PICANÇO, Felícia; MORAIS, Juliana. Estudos sobre estratificação educacional: síntese dos principais argumentos e desdobramentos. Educação \& Sociedade, [s.I.], v. 37, n. 135, p.391-406, jun. 2016. FapUNIFESP (SciELO).

PRATES, Antônio Augusto Pereira \& COLLARES, Ana Cristina Murta. Desigualdade e expansão do ensino superior na sociedade contemporânea: 0 caso brasileiro do final do século XX ao princípio do século XXI. Belo Horizonte, Fino Traço, 2014.

RABELO, Rachel Pereira. Desigualdades sociais no ensino superior: explorando tendências e impactos da lei de cotas. In: REUNIÃO NACIONAL ANPED, 38., 2017, São Luís. Anais.... São Luís: Anped, 2017. v. 1, p. 1 - 22. Disponível em: <http://anais.anped.org.br/sites/default/files/arquivos/ trabalho_38anped_2017_GT11_1146.pdf>. Acesso em: 10 abr. 2018.

RIBEIRO, Carlos Antonio Costa; SCHLEGEL, Rogerio. Estratificação horizontal da Educação Superior no Brasil (1960 a 2010). In: ARRETCHE, M. Trajetórias das Desigualdades: como o Brasil mudou nos últimos cinquenta anos. São Paulo: Editora Unesp/CEM, 2015. p. 133-162.

RIBEIRO, Carlos Costa; CENEVIVA, Ricardo; BRITO, Murillo Marschner Alves de. Estratificação educacional entre jovens no Brasil: 1960 a 2010. In: ARRETCHE, M. Trajetórias das Desigualdades: como o Brasil mudou nos últimos cinquenta anos. São Paulo: Editora Unesp/CEM, 2015. p. 79-108. 


\section{movimento \\ faculdade de educação - programa de pós-graduação em educação \\ universidade federal fluminense \\ issn 2359-3296 \\ ano 5 número 9 - 2018}

RISTOFF, Dilvo. Democratização do campus: impacto dos programas de inclusão sobre o perfil da graduação. Cadernos do GEA. Rio de Janeiro, n. 9, jan./jun. 2016.

SAMPAIO, Helena. Novas dinâmicas do ensino superior no Brasil: o público e o privado. Cadernos do GEA. Rio de Janeiro, n. 7, jan./jun. 2015.

TRIVENTI, Moris. Stratification in Higher Education and Its Relationship with Social Inequality: A Comparative Study of 11 European Countries. European Sociological Review, [s.I.], v. 29, n. 3, p.489-502, 20 dez. 2011. Oxford University Press (OUP).

\section{SOBRE OS AUTORES}

LUCINETE LIMA. é Doutora em Educação pela Universidade Estadual Paulista Júlio de Mesquita. Professora da Universidade Federal do Maranhão

E-mail: lucinete.ml@ufma.br

ANGELO BIANCHIN é Doutor em Educação - Universidade Estadual Paulista Júlio de Mesquita. Professor da Universidade Federal do Maranhão.

E-mail: ar.bianchini@ufma.br

ELLEN PANTOJA é Doutoranda do Programa de Pós-Graduação em Educação da Universidade Federal Fluminense. Professora da Universidade Federal do Maranhão.

E-mail: ellenpantoja@gmail.com

Recebido em: 23.07.2018

Aceito em: 10.09.2018 